Article

\title{
Sensory Profile of Rice-Based Snack (Nuroongji) Prepared from Rice with Different Levels of Milling Degree
}

\author{
Mina K. Kim \\ Department of Food Science and Human Nutrition and Fermented Food Research Center, \\ Jeonbuk National University, 567 Baekjedaero, Deokjin-gu, Jeonju-si, Jeonbuk 54896, Korea; \\ minakim@jbnu.ac.kr; Tel.: +82-63-270-3879
}

Received: 22 April 2020; Accepted: 20 May 2020; Published: 26 May 2020

\begin{abstract}
Nuroongii is a traditional rice-based snack that is widely consumed in Korea, but there is no reported comprehensive sensory characterization of this popular snack. The objective of this study was to conduct a sensory analysis of Nuroongji made with rice with different degrees of milling. Four different types of Nuroongji samples according to the degree of milling were prepared in the lab and subjected to physiochemical analysis. Descriptive sensory analysis was conducted by a trained panel $(n=8)$, and a consumer acceptance test was conducted using college students $(n=70)$. A sensory lexicon describing the flavor and texture characteristics of Nuroongji was developed: it included roasted brown rice, burnt, buckwheat, rice powder, glutinous rice power, and floral. The following texture attributes were evaluated in triplicate: hardness of particles, irregularity of particles, degree of coagulation, number of chews, and residual mouthfeel. Significant differences in flavor and mouthfeel attributes were observed between the Nuroongji samples according to the degree of milling $(p<0.05)$. Nuroongii made with white rice $(\mathrm{N} 1)$ had a higher hardness value and less sweetness compared to other samples $(p<0.05)$. Texture- and mouthfeel-related attributes such as cohesiveness of the mass, irregularity of the surface, and astringency were identified as important characteristics that drive consumer acceptance of Nuroongji products. Findings from this study can provide Nuroongii product developers a valuable insight to extend their market by reformulating the product to be appealing to young consumers.
\end{abstract}

Keywords: Nuroongji; rice snack; descriptive analysis; consumer acceptance testing; consumer studies; texture; mouthfeel

\section{Introduction}

The market for gluten-free products is increasing as consumer awareness toward health and wellness increases. Approximately $1 \%-2 \%$ of the population in Western countries is suffering from celiac disease [1] and this equates to about 2.1 million adults in the U.S. [2]. While gluten-free product choice is essential only for those who suffer from celiac disease, health-conscious consumers are also choosing gluten-free products as healthier alternatives for their regular wheat-based products [3]. This indicates that food choice behavior among consumers is affected by not only sensory but also non-sensory factors including psychological factors [4], context of food consumption [5], emotional affects [6], and sustainability [7]. Sensory and non-sensory factors influence consumer food choice behavior and understanding factors affecting the food choice is crucial for market success. Due to the rise of the gluten-free market, products with gluten-free options are well studied, these include, prebiotic gluten-free bread [1] and gluten-free bread with different functional food additives [8,9] or lactic acid cultures [10]. These gluten-free options of wheat-based products do not completely mimic 
the sensory characteristics of their standard counterpart products. Studies reported that gluten-free version of wheat-based food products are more costly $[11,12]$ and several products were contaminated with gluten in gluten-free products [13]. While there are limitations on gluten-free alternatives of standard wheat-based products, processed rice products are naturally non-gluten containing and can be served as gluten-free products in nature.

Nuroongji is a traditional rice-based snack that is widely consumed in Korea. It is typically had as an accompaniment to tea or soup [14]. Nuroongji is the scorched rice that is left at the bottom of the cooker [15]. Traditionally, this scorched rice was scratched off the bottom of the cooker and eaten as a snack. The traditional method of making Nuroongji is highly dependent on what is left at the bottom of the rice cooker; therefore, the sensory quality and/or quantity of traditionally made Nuroongii is not well controlled. Recently, companies have started to mass-produce Nuroongji, and the typical method of commercially preparing it is as follows: Rice is washed, soaked in water for 30-40 min, and cooked. The cooked rice is pressed in a heated device that resembles a waffle-maker. The cooked rice is roasted and dried as a result of the heated pressing device, and this is how the brown and crispy characteristics of Nuroongji are achieved [16]. This process of browning and crisping can be explained by the Maillard browning reaction [15]. There have been extensive sensory studies on cooked rice, but very little research has been conducted on the sensory characteristics of Nuroongji. The summary of previously reported studies on Nuroongji can be found in Table 1.

Table 1. Summary of previous research on Nuroongji products.

\begin{tabular}{|c|c|c|}
\hline Authors & Subject Studied & Key Finding \\
\hline Suh et al. (1996) [16] & Cooking conditions of Nuroongji & $\begin{array}{l}\text { Nuroongii prepared with cabinet cooker } \\
\text { showed higher consumer preference } \\
\text { Physiochemical characteristics of instant }\end{array}$ \\
\hline Park and Oh (1997) [17] & Instant Nuroongji & $\begin{array}{l}\text { Nuroongji made with steam cooker, pressure } \\
\text { cooker, and cabinet cooker were documented }\end{array}$ \\
\hline Cha (1999) [18] & Processing method for Nuroongji & $\begin{array}{l}\text { Processing conditions such as hydrolysis with } \\
\alpha \text {-amylase and gelatinization of rice powder } \\
\text { for Nuroongji preparation were studied }\end{array}$ \\
\hline Lee et al. (2009a) [19] & $\begin{array}{l}\text { Instant Nuroongji with added } \\
\text { Dioscorea japonica powder }\end{array}$ & $\begin{array}{l}\text { Quality characteristics of Nuroongii made } \\
\text { with varying levels of Dioscorea japonica } \\
\text { powder }(2 \%, 4 \%, 6 \%, 8 \%) \text { were profiled }\end{array}$ \\
\hline Lee et al. (2009b) [20] & $\begin{array}{l}\text { Instant Nuroongii prepared using a } \\
\text { microwave }\end{array}$ & $\begin{array}{l}\text { Quality characteristics of instant Nuroongji } \\
\text { prepared by microwave, steam cooker, and } \\
\text { pressure cooker were compared }\end{array}$ \\
\hline Do et al. (2010) [14] & Nuroongji processing facilities & $\begin{array}{l}\text { High microbial contamination in the process } \\
\text { where employee interaction was required } \\
\text { Quality and sensory characteristics of }\end{array}$ \\
\hline Ha et al. (2012) [20] & $\begin{array}{l}\text { Nuroongji made from japonica rice } \\
\text { cultivars }\end{array}$ & $\begin{array}{l}\text { Nuroongji made with different types of rice } \\
\text { cultivars (Hopum, Shindongin, Daeribbyeo, } \\
\text { Chinnong, Boramchan, Deuraechan) }\end{array}$ \\
\hline Yang and Choi (2016) [15] & Five commercial Nuroongji products & $\begin{array}{l}\text { Antioxidant properties and physiochemical } \\
\text { properties including } \mathrm{pH} \text {, moisture, color were } \\
\text { profiled }\end{array}$ \\
\hline Choi et al. (2017) [21] & Pan bread with Nuroongji powder & $\begin{array}{l}\text { Quality characteristics of pan bread with } \\
\text { different levels of Nuroongji powder }(5 \% \text {, } \\
10 \%, 15 \%, 20 \%) \text { were studied }\end{array}$ \\
\hline Lee (2018) [22] & Nuroongji with green whole grain & $\begin{array}{l}\text { Quality characteristics of Nuroongji made } \\
\text { with green whole grain was profiled }\end{array}$ \\
\hline
\end{tabular}

These mentioned studies primarily focused on products with little additions to Nuroongji; therefore, sensory characterization was not well-considered. While previous study on Nuroongji only focused on quality characterization, many studies were conducted on sensory characterization of cooked rice with differing milling degrees. Previous study reported the effect of milling ratio on sensory characteristics of cooked rice, and documented 4 appearance-related terms (color, glossiness, intactness of grains, plumpness); 9 flavor attributes including boiled egg white, puffed corn, dairy, raw rice, wet cardboard, hay-like, metallic, sweet, and bitter tastes; and 10 texture-related attributes 
including degree of agglomeration, adhesiveness, roughness, hardness, cohesiveness, inner moisture, cohesiveness of mass, chewiness, toothpacking, and residuals [23]. Their study reported that degree of agglomeration, adhesiveness, inner moisture, toothpacking, and cohesiveness of mass of cooked rice increased with increased milling degree. Their work compared the instrumental texture analysis and sensory texture analysis data to comprehensively provide the texture profiles of cooked rice with different milling degrees. As Nuroongji is also a rice-based product, Nuroongji and cooked rice may share similar sensory characteristics, while there may also be inevitable differences in the sensory characteristics as a result of the additional processing. To our knowledge, sensory characterization of Nuroongji is lacking. Understanding sensory characteristics of Nuroongji can provide valuable insights to those who are seeking a healthier snack as well as those who are on gluten-free diets. Therefore, the objective of this study was to identify the sensory characteristics of Nuroongii made with rice subjected to different degrees of milling. Descriptive sensory analyses using a well-trained sensory panel and consumer acceptance testing were carried out in order to identify the sensory characteristics that drove consumer liking of Nuroongji.

\section{Materials and Methods}

\subsection{Preparation of Nuroongji Samples}

Rice (Oryza sativa subsp. japonica cultivar Koshihikari) harvested in Gimje, Jeollabukdo, was purchased directly from a supplier. This supplier does not mill the rice upon harvesting, and the stored brown rice is milled according to the requirement of the customer. Brown rice, white rice, $50 \%$ milled rice, and $70 \%$ milled rice were prepared by the supplier on order and were shipped to the lab immediately after milling. The different rice samples were refrigerated to minimize the possibility of the formation of an oxidized note. The Nuroongji samples were prepared in the lab using a Nuroongji maker (BE-7200; Bethelcook, Hwasung, Korea). In order to make Nuroongji, the four rice samples were washed three times with tap water and soaked in water for $40 \mathrm{~min}$ at $20^{\circ} \mathrm{C}$. Then, the rice was cooked for $40 \mathrm{~min}$ at $110^{\circ} \mathrm{C}$ using a rice cooker (PERW-20L, PN; Ansan, Gyeonggi-do, Korea) following the manufacturer's recommended method of cooking. Upon cooking, $42.5 \mathrm{~g}$ of cooked rice (1.5 oz) was scooped out using an ice cream scooper (\#20, Minyong Corp. Jeonju, Korea) and was immediately transferred to the Nuroongji maker (BE-7200, Bethel Electronics, Hwaseong-si, Gyeonggi-do, Korea), in which it was pressed for $4 \mathrm{~min}$. The pressed rice removed from the Nuroongji maker is the commercially available crispy snack $(6.5 \mathrm{~cm} \times 12 \mathrm{~cm} \times 0.2 \mathrm{~cm})$ that is referred to as Nuroongii. Nuroongii made with unmilled brown rice was labeled as N1; Nuroongji made with $50 \%$ milled rice was labeled as N2; Nuroongji made with $70 \%$ milled rice was labeled as N3; and Nuroongji made with white rice was labeled as N4. A total of 20 Nuroongji snacks $(6.5 \mathrm{~cm} \times 12 \mathrm{~cm} \times 0.2 \mathrm{~cm})$ were prepared for physiochemical analysis, and 200 Nuroongji snacks were prepared for sensory analysis in order to minimize the batch-to-batch variability.

Once the Nuroongji samples were prepared, they were additionally cooked for further analysis. Based on a comprehensive review of cook books, online recipes, and other sources of information, the following cooking method was used: $25 \mathrm{~g}$ of crushed Nuroongji was added to $500 \mathrm{~mL}$ of cold water in a pot $(5 \% \mathrm{w} / \mathrm{v})$ and boiled for $10 \mathrm{~min}$ with the lid on. Immediately after cooking, the samples were kept in a warming cabinet set at a temperature of $60^{\circ} \mathrm{C}$ for further analysis.

\subsection{Physiochemical Analysis of Nuroongji Samples}

Physiochemical analysis of $\mathrm{pH}$, moisture content, color, and water-binding capacity was conducted using standard methods of analysis. Briefly, the $\mathrm{pH}$ of the Nuroongji samples was measured with a $\mathrm{pH}$ meter (Lab 850; Schott, Germany) after filtering 10\% (w/v, with distilled water) diluted Nuroongji through a filter paper (Whatman No. 2; Maidstone, UK). Moisture content was measured using a moisture analyzer (WBA-110M; Daihan, Korea), and color was analyzed using a color analyzer (CR-10; Minolta, Osaka, Japan). A color value standard plate was used with values $L^{*}=97.51, a^{*}=-5.26$, 
and $b^{*}=+7.00$. For moisture content analysis, the Nuroongji sample was crushed to a powder (that could pass through a mesh 30 ) and tightly packed in a clear container designated for the color analyzer, and $L^{*}, a^{*}, b^{*}$ values of the Nuroongji samples were measured. The water-binding capacity of Nuroongji was assessed using the method from previous study [15]. Briefly, the Nuroongii sample was crushed to a powder (that could pass through a mesh 30), and $0.5 \mathrm{~g}$ of the powder was added to $30 \mathrm{~mL}$ of distilled water. It was then mixed thoroughly with a magnetic stirrer for $1 \mathrm{~h}$ at room temperature. Once thoroughly mixed, this mixture was centrifuged at $3000 \times g$ for $30 \mathrm{~min}$, and the supernatant was removed. The weight of the solid residue was measured, and the ratio of the solid residue to the powder was considered as the water-binding capacity $(\%)$. All analyses were conducted in triplicate.

\subsection{Descriptive Sensory Analysis}

In the descriptive sensory analysis, the flavor and texture (mouthfeel) components of each of the four Nuroongji samples were evaluated by a well-trained panel of eight members (two males and six females aged 22-40 years). Each panelist was recruited as part of a taster club in Jeonbuk National University in 2016 and were screened based on their interests and ability of basic taste recognition and odor recognition. Panelists were initially trained for $80 \mathrm{~h}$ in the Spectrum ${ }^{\mathrm{TM}}$ method. After initial training, panelists have been participating the sensory evaluation of various food products. Prior to the evaluation, each panelist received $40 \mathrm{~h}$ of training with a basic taste solution for aroma recognition, aroma expression, and intensity rating with the universal scale used in the Spectrum ${ }^{\mathrm{TM}}$ method. In addition to training, eight $2 \mathrm{~h}$ training sessions were held to generate a sensory lexicon for flavor and texture as well as a method for evaluating the textural attributes of the Nuroongji samples. Separate sensory lexicons were generated for flavor and texture with various reference samples including food and chemical references. For the flavor lexicon, references were provided for each attribute in order to minimize the panelist-to-panelist variation resulting from aroma recognition and expression. Texture attributes were evaluated following previous texture evaluation protocols for rice with some modifications [24]. Briefly, panelists evaluated the texture attributes via a three-stage approach: In stage 1, they evaluated the "hardness" and "irregularity" of the Nuroongji sample by pressing the sample against their tongue. In stage 2 , another spoonful $(\sim 6 \mathrm{~g})$ of the sample was placed in the mouth in order to evaluate the "cohesiveness" of the particles while chewing. Finally, in stage 3 , another spoonful ( $\sim 6 \mathrm{~g})$ of the Nuroongji sample was placed in the mouth, in order to evaluate the "number of chews" before swallowing (or spitting) and "residual mouthfeel" upon swallowing (or spitting).

The Nuroongji samples were cooked using the method mentioned earlier: $25 \mathrm{~g}$ of the Nuroongji sample was added to $500 \mathrm{~mL}$ of cold water in a pot $(5 \% \mathrm{w} / \mathrm{v})$ and boiled for $10 \mathrm{~min}$ with the lid on. Different batches of Nuroongji were crushed and mixed thoroughly before cooking in order to minimize the batch-to-batch variation. Immediately after cooking, $50 \mathrm{~mL}$ of the samples was poured into a $195 \mathrm{~mL}$ paper cup (Jin-kwang Papers; Paju, Gyeonggi-do, Korea) that was labeled with a three-digit random code and covered with a lid, and kept in the warming cabinet set at $60^{\circ} \mathrm{C}$. All samples were prepared $30 \mathrm{~min}$ prior to evaluation, and the samples were served and evaluated at $60^{\circ} \mathrm{C}$. Panelists were asked to evaluate the flavor attributes in triplicate, and separate sessions were held for texture evaluation.

For texture evaluation, the panelists were asked to place a spoonful of the sample and follow the three-stage approach described above. All the samples were evaluated in triplicate by each panelist $(n=6)$ with a randomized, balanced design. A 2 min rest was enforced between samples in order to minimize the carry-over effect in the flavor evaluation session. The panelists recorded their intensity ratings on a paper ballot, and scored on the 15-point universal scale of the Spectrum ${ }^{\mathrm{TM}}$ method. Upon completion of the flavor and texture evaluation, the panelists were invited to an appreciation dinner as compensation for their participation in the analysis. 


\subsection{Consumer Acceptance Testing}

For consumer acceptance testing of the four Nuroongji samples, a total of 70 consumers participated. Participants were recruited from Jeonbuk National University-Jeonju campus through flyers, SNS postings, and personal contacts. The majority of the participants were active members of the Food Taster Club operated by Jeonbuk National University-Sensory Service Center, and hence, they were undergraduate students. Participants in this study did not represent the Korean population, as majority of participants were college students. Drawing a conclusion based on the consumer acceptance testing data from this study may pose a risk of potential bias. Although the potential bias of participant sampling exists, participants were screened to ensure that they were either users of Nuroongji products (consume such products at least one a month) or at least a product acceptor. The Nuroongji samples were prepared using the same protocol used in the descriptive sensory analysis. In order to keep the consistency of cooked Nuroongji, participants were pre-scheduled for their evaluation time. All samples were prepared $30 \mathrm{~min}$ prior to consumer testing, and the samples were served in a paper cup with the lid on and labeled with a three-digit random code (as described for the descriptive sensory analysis). Samples were served monadically, and the order of presentation was randomized and balanced.

On the day of testing, participants were asked to fill out a brief demographic questionnaire prior to evaluation, and then asked to visually evaluate the appearance and color of the Nuroongji samples. The participants were asked to rate their responses to the following attributes: appearance and color likings; overall liking; and other likings such as flavor, texture, spreadability, and stickiness. Their responses were scored on a nine-point hedonic scale with 1 indicating dislike extremely, 5 indicating neither dislike nor like, and 9 indicating like extremely, as suggested by previous study [25].

\subsection{Statistical Analysis}

Results were expressed as mean values from triplicate analyses of the physiochemical properties of the samples. Mean values of flavor and texture from the triplicate evaluations by each panelist $(n=8)$ were reported for the descriptive sensory analysis, and the mean liking scores collected from the 70 consumer test participants were reported. Analysis of variance followed by Fisher's least significant difference (for the physiochemical analysis) and Tukey's honestly significant difference (for the descriptive sensory analysis and the consumer acceptance test) was conducted at the $\alpha=0.05$ level. Partial least square regression was conducted with the overall liking score as a single Y-axis variable and the physiochemical attributes and sensory flavor and texture attributes as $\mathrm{X}$-axis variables, under the assumption that each $X$ variable had an equal chance of influencing the model. All statistical analyses were conducted using XLSTAT (v.2019; Addinsoft, Paris, France).

\section{Results and Discussion}

\subsection{Physiochemical Analysis}

The physiochemical analysis results for the Nuroongji samples can be found in Table 2. Significant differences in physiochemical properties were observed between the Nuroongji samples $(p<0.05)$. Briefly, the $\mathrm{pH}$ of the Nuroongji samples ranged from 6.32 to 6.61 , with $\mathrm{N} 1$ having the highest $\mathrm{pH}$ value and N3 having the lowest value $(p<0.05)$. The moisture content of the Nuroongji samples exhibited significant differences: $\mathrm{N} 2$ and $\mathrm{N} 4$ had a significantly higher moisture content than $\mathrm{N} 1$ and $\mathrm{N} 3(\mathrm{~N} 2=9.07 \%, \mathrm{~N} 4=8.39 \%, \mathrm{~N} 3=5.93 \%, \mathrm{~N} 1=5.54 \%)$. It must be noted that all the samples were prepared with the same method and the same machine and were prepared within a period of 1 week, so any differences in moisture content were unlikely to be associated with the preparation method. The water-binding capacity also showed significant differences: N3 and N4 had the highest water-binding capacities, while N1 had the lowest water-binding capacity $(253.3 \%)(p<0.05)$. The low moisture content (5.93\%) of N3 may have influenced its high water-binding capacity (486.7\%). 
Previously, it was reported that the water-binding capacity of Nuroongji was inversely correlated with the protein content of rice [20]. Additionally, the protein content of brown rice is higher than that of white rice and rice with different degrees of milling [20]. This might explain the low water-binding capacity of N1, as N1 was unmilled brown rice.

Table 2. Physiochemical properties of Nuroongii samples.

\begin{tabular}{cccccccccc}
\hline & \multirow{2}{*}{$\mathbf{p H}$} & \multirow{2}{*}{$\begin{array}{c}\text { Moisture } \\
\text { (\%) }\end{array}$} & Water-Binding & \multicolumn{3}{c}{ Before Cooking } & \multicolumn{3}{c}{ After Cooking } \\
\cline { 6 - 10 } & & & Capacity (\%) & $\boldsymbol{L}^{*}$ & $\boldsymbol{a}^{*}$ & $\boldsymbol{b}^{*}$ & $\boldsymbol{L}^{*}$ & $\boldsymbol{a}^{*}$ & $\boldsymbol{b}^{*}$ \\
\hline $\mathrm{N} 1$ & $6.61 \mathrm{a}$ & $5.54 \mathrm{~b}$ & $253.3 \mathrm{c}$ & $67.97 \mathrm{a}$ & $6.70 \mathrm{a}$ & $24.3 \mathrm{a}$ & $6.70 \mathrm{~b}$ & $3.60 \mathrm{~b}$ & $5.97 \mathrm{~b}$ \\
$\mathrm{~N} 2$ & $6.50 \mathrm{ab}$ & $9.07 \mathrm{a}$ & $346.7 \mathrm{bc}$ & $68.13 \mathrm{a}$ & $3.83 \mathrm{~b}$ & $16.30 \mathrm{~b}$ & $9.40 \mathrm{~b}$ & $2.60 \mathrm{c}$ & $5.90 \mathrm{~b}$ \\
$\mathrm{~N} 3$ & $6.32 \mathrm{c}$ & $5.93 \mathrm{~b}$ & $486.7 \mathrm{a}$ & $57.50 \mathrm{~b}$ & $7.30 \mathrm{a}$ & $19.63 \mathrm{ab}$ & $13.33 \mathrm{a}$ & $4.30 \mathrm{a}$ & $9.13 \mathrm{a}$ \\
$\mathrm{N} 4$ & $6.45 \mathrm{~b}$ & $8.39 \mathrm{a}$ & $460.0 \mathrm{ab}$ & $71.47 \mathrm{a}$ & $3.80 \mathrm{~b}$ & $17.13 \mathrm{~b}$ & $15.90 \mathrm{a}$ & $2.43 \mathrm{c}$ & $6.37 \mathrm{~b}$ \\
\hline
\end{tabular}

Numbers represent the mean values of triplicate analyses of each physiochemical attributes; means in a column that do not share the same alphabet represent significant differences at the $\alpha=0.05$ level; N1 represents the Nuroongji made with unmilled brown rice; N2 represents Nuroongji made with 50\% milled rice; N3 represents Nuroongii made with $70 \%$ milled rice; N4 represents Nuroongji made with white rice.

The color of the Nuroongji samples also showed significant differences $(p<0.05)$. Before cooking, the $L^{*}$ value of the samples ranged from 57.50 to 71.47; the $a^{*}$ value ranged from 16.30 to 24.3; and the $b^{*}$ value ranged from 6.70 to 15.90 . These values were in agreement with previously reported values $[17,26,27]$. After cooking, the $L^{*}$ of the Nuroongji samples ranged from 6.70 to 15.90 ; the $a^{*}$ value ranged from 2.43 to 4.30 ; and the $b^{*}$ value ranged from 5.90 to 9.13 . Before cooking, the $L^{*}$ value of N3 was the lowest; this indicates that it was darker in color $(p<0.05)$. The $b^{*}$ value of N1 was the highest at 24.3, which is indicative of a yellowish color. N1 was made with brown rice; therefore, the yellow color could be attributed to the rice germ that was remaining in the brown rice.

\subsection{Descriptive Sensory Analysis}

The descriptive sensory analysis results for the four Nuroongji samples can be found in Table 3 (flavor attributes) and Table 4 (texture attributes). A total of 12 flavor attributes, including 6 aromas, 5 basic tastes, and 1 mouthfeel attribute, were utilized to describe the flavor characteristics. Five texture-related attributes, including hardness, irregularity, cohesiveness, numbers of chews, and residual mouthfeel, were utilized to describe the texture characteristics.

The Nuroongii samples made with unmilled brown rice (N1) and 70\% milled rice (N3) shared similar flavor characteristics: that is, the aroma intensities for roasted brown rice and buckwheat tea were significantly higher than those of the other samples $(p<0.05)$, while the aroma intensities for rice powder and sticky rice powder were significantly lower than those of the other samples $(p<0.05)$. No differences were observed between N1 and N3 with regard to these four attributes $(p>0.05)$. When the aroma characteristics of N1 (Nuroongji made with brown rice) and N4 (Nuroongji made with white rice) were compared, the aroma intensity of roasted brown rice was significantly higher for N1 than for N4. A previous study on the attributes of seolgitteok, which is a type of Korean rice cake made by steaming rice flour, also reported higher levels of brown rice flavor in seolgitteok made with brown rice than in seolgitteok made with white rice [26]. The aroma intensities for rice powder and sticky rice powder were significantly higher in $\mathrm{N} 4$ than in the other samples $(p<0.05)$. Similarly, a previous study reported that the cooked rice flavor was higher in seolgitteok made with only white rice than in seolgitteok made with the addition of brown rice [26]. In the present study, a flowery aroma was noted in all the samples, and this flowery aroma has also previously been reported as an aroma attribute of cooked rice [27]. No significant differences were observed in basic tastes, except for sweet taste $(p>0.05)$ : the intensity of sweet taste was the highest (1.99) for N4, which was followed by N2 (1.66), N3 (1.52), and N1 (1.10), which had the lowest sweet taste intensity $(p<0.05)$. In agreement with these findings, a previous study on descriptive analysis of cooked rice with differing degrees of milling also reported that cooked white rice had a more intense sweet taste than cooked brown rice $[17,28]$. 
Table 3. Descriptive sensory flavor analysis results on Nuroongii samples.

\begin{tabular}{|c|c|c|c|c|c|c|}
\hline Sensory Term & Definition & N1 & N2 & N3 & N4 & $p$-Value \\
\hline Roasted brown rice & $\begin{array}{c}\text { Typical aromatics associated with brown rice puff (Ref: roasted brown rice DuriDuri from } \\
\text { Hansum Healthy Food Cooperative, Nonsan, Chungnam, Korea) }\end{array}$ & $2.6 \mathrm{a}$ & $1.3 \mathrm{~b}$ & $2.6 \mathrm{a}$ & $0.8 \mathrm{c}$ & $<0.0001$ \\
\hline Burnt & Typical aromatics associated with burnt wood (Ref.: burnt match) & $1.1 \mathrm{~b}$ & $0.8 \mathrm{~b}$ & $1.6 \mathrm{a}$ & $0.2 \mathrm{c}$ & $<0.0001$ \\
\hline Buckwheat tea & $\begin{array}{c}\text { Typical aromatics associated with buckwheat tea (Ref: buckwheat tea from Dongseo, Siheung, } \\
\text { Gyeonggi-do, Korea) }\end{array}$ & $2.2 \mathrm{a}$ & $1.6 \mathrm{~b}$ & $2.2 \mathrm{a}$ & $1.3 \mathrm{~b}$ & $<0.0001$ \\
\hline Rice powder & $\begin{array}{c}\text { Typical aromatics associated with rice powder (Ref: organic rice powder from Mom's rice, } \\
\text { Gwangju, Gyeonggi-do, Korea) }\end{array}$ & $1.0 \mathrm{c}$ & $1.7 \mathrm{~b}$ & $1.0 \mathrm{c}$ & $2.4 \mathrm{a}$ & $<0.0001$ \\
\hline Sticky rice powder & $\begin{array}{l}\text { Typical aromatics associated with sticky rice powder (Ref: organic sticky rice powder from } \\
\text { Mom's rice, Gwangju, Gyeonggi-do, Korea) }\end{array}$ & $0.5 \mathrm{c}$ & $1.3 \mathrm{~b}$ & $0.6 \mathrm{c}$ & $2.0 \mathrm{a}$ & $<0.0001$ \\
\hline Flowery & Typical aromatics associated with chamomile tea (Ref: chamomile tea from e-mart, Seoul, Korea) & $0.7 \mathrm{c}$ & $1.8 \mathrm{a}$ & $1.1 \mathrm{bc}$ & $1.5 \mathrm{ab}$ & $<0.0001$ \\
\hline Sweet & $\begin{array}{l}\text { Fundamental taste sensation of which sucrose is typical (sweet } 2=1 \%(\mathrm{w} / \mathrm{v}) \text { sucrose solution, } \\
\text { sweet } 5=5 \%(\mathrm{w} / \mathrm{v}) \text { sucrose solution) }\end{array}$ & $1.1 \mathrm{c}$ & $1.7 \mathrm{~b}$ & $1.5 \mathrm{~b}$ & $2.0 \mathrm{a}$ & $<0.0001$ \\
\hline Sour & $\begin{array}{l}\text { Fundamental taste sensation of which acetic acid is typical (sour } 2=0.05 \%(\mathrm{w} / \mathrm{v}) \text { sucrose solution, } \\
\text { sour } 5=0.08 \%(\mathrm{w} / \mathrm{v}) \text { sucrose solution) }\end{array}$ & $0.3 \mathrm{a}$ & $0.4 \mathrm{a}$ & $0.5 \mathrm{a}$ & $0.5 \mathrm{a}$ & 0.127 \\
\hline Salty & $\begin{array}{c}\text { Fundamental taste sensation of which sodium chloride is typical (salty } 2=0.36 \%(\mathrm{w} / \mathrm{v}) \text { salt } \\
\text { solution, salty } 5=0.5 \%(\mathrm{w} / \mathrm{v}) \text { salt solution) }\end{array}$ & $0.4 \mathrm{a}$ & $0.3 \mathrm{a}$ & $0.5 \mathrm{a}$ & $0.4 \mathrm{a}$ & 0.793 \\
\hline Bitter & $\begin{array}{l}\text { Fundamental taste sensation of which caffeine is typical (bitter } 2=0.05 \%(\mathrm{w} / \mathrm{v}) \text { caffeine solution, } \\
\text { bitter } 5=0.08 \%(\mathrm{w} / \mathrm{v}) \text { caffeine solution) }\end{array}$ & $0.6 \mathrm{a}$ & $0.3 \mathrm{a}$ & $0.4 \mathrm{a}$ & $0.2 \mathrm{a}$ & 0.750 \\
\hline Umami & $\begin{array}{c}\begin{array}{c}\text { Fundamental taste sensation of which monosodium glutamate is typical (umami } 3=5 \%(\mathrm{w} / \mathrm{v}) \\
\text { monosodium glutamate solution) }\end{array}\end{array}$ & $0.6 \mathrm{a}$ & $0.6 \mathrm{a}$ & $0.6 \mathrm{a}$ & $0.6 \mathrm{a}$ & 0.980 \\
\hline Astringency & Drying mouthfeel on a tongue that is associated with tannins $(0.1 \%$ tannic acid) & $1.8 \mathrm{~b}$ & $2.4 \mathrm{a}$ & $1.9 \mathrm{~b}$ & $0.2 \mathrm{c}$ & $<0.0001$ \\
\hline
\end{tabular}

Numbers represent the mean values of triplicate analyses of each sensory term; means in a row that do not share the same alphabet represent significant differences at the $\alpha=0.05$ level;

N1 represents the Nuroongji made with unmilled brown rice; N2 represents Nuroongji made with 50\% milled rice; N3 represents Nuroongji made with $70 \%$ milled rice; N4 represents Nuroongji made with white rice.

Table 4. Descriptive sensory texture analysis results on Nuroongji samples.

\begin{tabular}{|c|c|c|c|c|c|c|c|}
\hline \multicolumn{2}{|c|}{ Sensory Term } & Definition & N1 ${ }^{(6)}$ & N2 & N3 & N4 & $p$-Value ${ }^{(5)}$ \\
\hline \multirow{2}{*}{ Stage $1^{(1)}$} & Hardness & Force required to break the rice particles with tongue & $11.4^{(4)} \mathrm{a}$ & $6.8 \mathrm{~b}$ & $5.9 \mathrm{~b}$ & $3.1 \mathrm{c}$ & $<0.0001$ \\
\hline & Irregularity & Degree of irregularity of particle breakdown pattern & $2.1 \mathrm{c}$ & $5.2 \mathrm{ab}$ & $5.9 \mathrm{a}$ & $4.1 \mathrm{~b}$ & $<0.0001$ \\
\hline Stage $2^{(2)}$ & Cohesiveness & Degree of which samples sticks together in a mass while chewing & $5.5 \mathrm{a}$ & $5.2 \mathrm{a}$ & $5.3 \mathrm{a}$ & $6.0 \mathrm{a}$ & 0.989 \\
\hline \multirow{2}{*}{ Stage $3^{(3)}$} & \# of chews & Numbers of chews required before spit (or swallow) & $58.7 \mathrm{a}$ & $42.7 \mathrm{~b}$ & $38.3 \mathrm{bc}$ & $34.3 \mathrm{c}$ & $<0.0001$ \\
\hline & Residual mouthfeel & Amount of residual particles left in the mouth after spit (or swallow) & $5.1 \mathrm{a}$ & $4.4 \mathrm{ab}$ & $4.0 \mathrm{~b}$ & $3.0 \mathrm{c}$ & $<0.0001$ \\
\hline
\end{tabular}

(1) Place a spoonful of Nuroongii sample $(\sim 6 \mathrm{~g})$ in mouth and press the particles with tongue; ${ }^{(2)}$ place a spoonful of Nuroongii sample $(\sim 6 \mathrm{~g})$ in mouth and evaluate while chewing; ; $^{(3)}$ place a spoonful of Nuroongji sample ( $\sim 6 \mathrm{~g})$ and evaluate during and after swallowing; ${ }^{(4)}$ numbers represent the mean values of triplicate analyses of each sensory term; ${ }^{(5)}$ means in a row that do not share the same alphabet represent significant differences at the $\alpha=0.05$ level; ${ }^{(6)} \mathrm{N} 1$ represents the Nuroongii made with unmilled brown rice; N2 represents Nuroongii made with $50 \%$ milled rice; N3 represents Nuroongji made with 70\% milled rice; N4 represents Nuroongji made with white rice. 
With regard to the texture attributes, similar attributes that are used to describe cooked rice were utilized to describe the present Nuroongi samples (Table 4). For example, as mentioned earlier, the three-stage approach for evaluating cooked rice that was proposed by previous study [17] was utilized: the degree of agglomeration, adhesiveness, roughness, hardness, cohesiveness, and inner moisture was assessed in stage 1; the cohesiveness of the mass and chewiness were assessed at stage 2; and toothpacking and residuals were evaluated at stage 3. Additionally, three other texture-related terms, that is, hardness, number of chews (defined as "chewiness" in the previous study), and cohesiveness and residual mouthfeel (residuals) were similar to previously reported texture attributes for cooked rice [23]. Significant differences were observed between the present samples with regard to hardness, irregularity, number of chews, and residual mouthfeel $(p<0.0001)$. N1 had the highest hardness value, and the difference was significant compared to the other samples $(p<0.0001)$. Accordingly, a previous study also reported that brown rice had a higher hardness value than white rice $[23,28]$.

\subsection{Consumer Acceptance Testing}

The results of the consumer acceptance test can be found in Table 5. A total of 70 consumers participated, and all of them were either users of Nuroongji products or were open to using them. Significant differences were observed in all the liking attributes $(p<0.05)$. Briefly, the overall liking scores of N2 and N3 were similar $(p>0.05)$ at 6.2 and 6.0, respectively. However, the overall liking score of N1 was significantly lower than that of $\mathrm{N} 2$ and N3, and N4 had the lowest overall liking score at $4.6(p<0.0001)$. Significant differences were observed in appearance-related attributes: N4 had the lowest appearance liking score (4.3) and color liking score (4.1), and the difference in the scores were significant in comparison with those for $\mathrm{N} 1, \mathrm{~N} 2$, and N3 $(p<0.0001)$. In agreement with these findings, a previous study on the appearance and aroma characteristics of raw rice reported that highly milled rice was rated as being glossier than non- and/or lightly milled rice or brown rice after cooking [27]. Additionally, it has been reported that consumers preferred yellow instant Nuroongji to instant Nuroongji of a white color [17]. Similar to the trends for appearance and color liking, $\mathrm{N} 4$ received the lowest flavor liking score (4.6), and the difference was significant in comparison with those for N1, N2, and N3 $(p<0.0001)$. N2 remained at the top of the list with regard to the flavor liking score (6.6). With regard to the texture-related attributes texture, spreadability, and stickiness, N1 received the lowest liking scores of $4.9,4.3$, and 4.8, respectively. These scores were significantly lower than those of the other samples for all three attributes $(p<0.0001)$. This is as expected because previous study reported that consumers preferred Nuroongji with low hardness value when it is served in a soup type $(5 \%-10 \% \mathrm{w} / \mathrm{v}$ in hot water) [20].

Table 5. Consumer acceptance test results for Nuroongii samples.

\begin{tabular}{cccccc}
\hline & N1 & N2 & N3 & N4 & $p$-Value \\
\hline Appearance liking & $6.0 \mathrm{a}$ & $6.1 \mathrm{a}$ & $5.6 \mathrm{a}$ & $4.3 \mathrm{~b}$ & $<0.0001$ \\
Color liking & $6.2 \mathrm{ab}$ & $6.3 \mathrm{a}$ & $5.6 \mathrm{~b}$ & $4.1 \mathrm{c}$ & $<0.0001$ \\
Overall liking & $5.3 \mathrm{~b}$ & $6.2 \mathrm{a}$ & $6.0 \mathrm{a}$ & $4.6 \mathrm{c}$ & $<0.0001$ \\
Flavor liking & $6.0 \mathrm{ab}$ & $6.6 \mathrm{a}$ & $5.4 \mathrm{~b}$ & $4.7 \mathrm{c}$ & $<0.0001$ \\
Texture liking & $4.9 \mathrm{~b}$ & $5.9 \mathrm{a}$ & $5.8 \mathrm{a}$ & $5.6 \mathrm{a}$ & $<0.001$ \\
Spreadability liking & $4.3 \mathrm{~b}$ & $5.4 \mathrm{a}$ & $5.9 \mathrm{a}$ & $5.6 \mathrm{a}$ & $<0.0001$ \\
Stickiness liking & $4.8 \mathrm{~b}$ & $5.5 \mathrm{a}$ & $5.9 \mathrm{a}$ & $5.4 \mathrm{a}$ & $<0.0001$ \\
\hline
\end{tabular}

Numbers in a row that does not share same alphabet represent significant differences at the $\alpha=0.05$ level. N1 represents the Nuroongji made with unmilled brown rice; N2 represents Nuroongji made with $50 \%$ milled rice; N3 represents Nuroongii made with 70\% milled rice; N4 represents Nuroongji made with white rice.

\subsection{Physiochemical and Sensory Attributes Driving Consumer Likings}

Partial least square regression analysis of the physiochemical analysis data, the sensory data obtained from the trained panel, and the overall consumer liking scores (Figure 1) showed that overall 
liking is best predicted by astringency and burnt aroma. Previous research on instant Nuroongji products has reported that a high degree of hardness showed the most significant correlation to consumer preference followed by yellow color of the instant Nuroongji sample [17]. However, the present findings did not clearly show a high correlation between overall liking and hardness or stickiness of Nuroongji products. Instead of flavor-related attributes, cohesiveness of the mass, irregularity of particles, and one mouthfeel attribute (astringency) were identified as important variables for consumer preference of Nuroongi. This is an interesting finding, because flavor remains the driver of liking for a majority of food products such as orange juice [29], chocolate milk [30], and Doenjang [31]. In contrast, the findings from this study indicated that texture and mouthfeel-related attributes, rather than flavor-related attributes, are important for consumers to determine their preference for Nuroongii products. This is also in agreement with the findings of previous studies on consumer preference for Nuroongji [16].

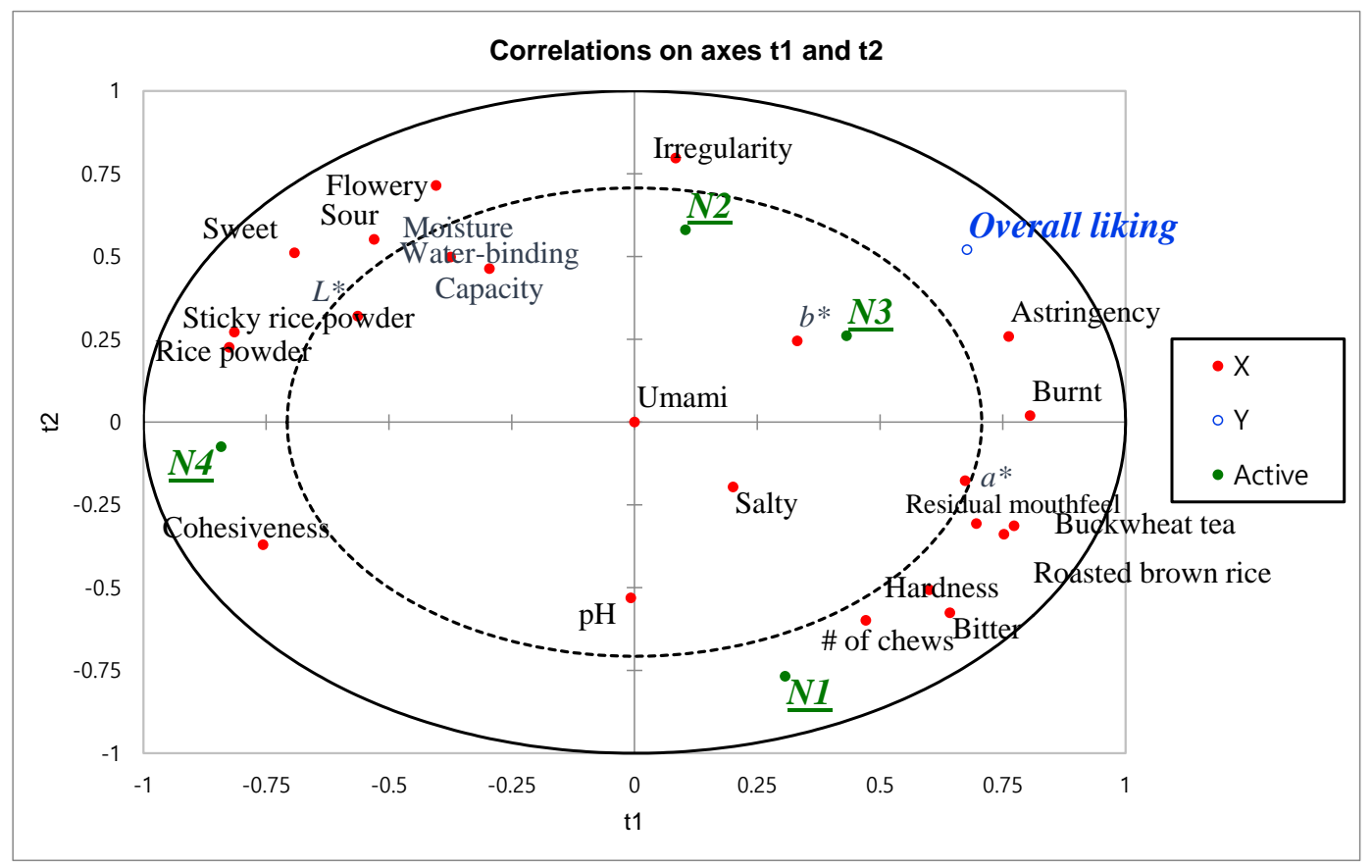

Figure 1. Partial least square regression on Nuroongji samples prepared with rice with different milling degree. N1 represents the Nuroongji made with unmilled brown rice; N2 represents Nuroongii made with 50\% milled rice; N3 represents Nuroongji made with 70\% milled rice; N4 represents Nuroongji made with white rice.

Texture attributes being drivers of consumer liking were previously documented in food commodities, especially the foods that offer healthier alternatives. Consumers preferred Greek yogurt with firm texture due to the increased protein content associated with firm yogurt [32]. Another study reported texture attributes such as creaminess, smoothness, cohesiveness, and mouth coating were important for consumer liking of spreadable cheese with varying fat contents [33]. Carbonated mouthfeel in lemon lime carbonated beverages was identified as a driver of liking among regular and diet beverage consumers. Softness of bread was also identified as a driver of liking for prebiotic gluten-free bread [1]. As seen in previous reports on drivers of liking of various food products, texture attributes became more important for consumers who seek healthier alternatives such as increased protein content [32], reduced fat [33], diet beverages [34], and gluten-free bread [1]. In the case of Nuroongji, which can be served as a gluten-free snack, texture attributes such as cohesiveness of the mass, irregularity of particles, and astringency were also identified as important variables for consumer liking. It is important to note that consumers who are seeking a healthier alternative do not want to sacrifice the sensory characteristics of the counterpart [35]. However, a product with healthier options 
(-free, - reduced, and -fortified) does not always created the same sensory characteristics in terms of flavor and texture, and this is a challenge in the food industry. Nuroongji, however, is naturally healthier snack in comparison to wheat-based snacks; therefore, there is no need for modification of the formulation for health-conscious consumers. Findings from this study suggest that texture-related attributes such as cohesiveness of the mass, irregularity of particles, and astringency are the key variables for consumer preference of Nuroongji, and this information can be useful for reformulating the Nuroongji to target consumers seeking gluten-free foods.

\section{Conclusions}

Differences in flavor and mouthfeel attributes were observed in Nuroongji products according to the degree of milling, and the differences were observed to a greater degree in the texture attributes. Importantly, the texture- and mouthfeel-related attributes cohesiveness of the mass, irregularity of the surface, and astringency were identified as important characteristics that drive consumer acceptance of Nuroongji products. Thus, texture, rather than flavor, seems to have a greater influence on consumer preference for Nuroongji products. Findings from this study can provide valuable information for market extension of Nuroongji toward consumers seeking gluten-free options. As stated earlier, food choice behavior is affected by various factors including sensory and non-sensory attributes. This study reported the sensory characteristics that drive consumer likings of Nuroongji using college students. The limitation of this study was the use of college students for consumer acceptance testing. Nuroongji is a traditional snack/tea in Korea, and the primary consumers of Nuroongji are older populations. In order to completely understand the consumer behavior, additional consumer testing using different consumer segments such as older populations and/or those who are actually on gluten-free diets is necessary in order to define the sensory drivers of liking of Nuroongji among the Korean population. This part will be done in a future study. In addition to sensory factors affecting Nuroongji, defining non-sensory factors affecting consumer purchase behavior of Nuroongji is another area of future study. Overcoming the "traditional" and "old" image of Nuroongji is another challenge for market extension. More research has to be done focused only on Nuroongji in order to expand the market share, and market expansion of Nuroongji can eventually promote the rice consumption in Korea, as Nuroongii is a processed rice product.

Funding: This work was supported by the Korea Institute of Planning and Evaluation for Technology in Food, Agriculture, Forestry, and Fisheries (IPET) through the High Value-added Food Technology Development Program, funded by the Ministry of Agriculture, Food, and Rural Affairs (MAFRA; grant \# 118012031SB010). Further, this work was also supported by the "Cooperative Research Program for Agriculture Science and Technology Development (project no. PJ013372042019)" under Rural Development Administration, Republic of Korea.

Conflicts of Interest: The authors declare no conflict of interest.

\section{References}

1. Morais, E.C.; Cruz, A.G.; Faria, J.A.F.; Bolini, H.M.A. Prebiotic bluten-free bread: Sensory profiling and drivers of liking. LWT-Food Sci. Technol. 2014, 55, 248-254. [CrossRef]

2. Pszczola, D.E. The rise of gluten-free ingredients. Food Technol. 2012, 66, 55.

3. Oltman, A.E.; Opetcharat, K.; Bastian, E.; Drake, M.A. Identifying key attributes for protein beverages. J. Food Sci. 2015, 80, S1383-S1387. [CrossRef] [PubMed]

4. Koster, E.P. Diversity in the determinants of food choice: A psychological perspective. Food Qual. Pref. 2007, 2, 70-82. [CrossRef]

5. Story, M.; Neumark-Sztainer, D.; French, S. Individual and environmental influences on adolescent eating behaviors. J. Acad. Nutr. Diet. 2002, 102, S40-S51. [CrossRef]

6. Leng, G.; Adan, R.A.; Belot, M.; Brunstrom, J.M.; De Graaf, K.; Dickson, S.L.; Hare, T.; Maier, S.; Menzies, J.; Preissl, H. The determinants of food choice. Proc. Nutr. Soc. 2017, 76, 316-327. [CrossRef] [PubMed]

7. Corallo, A.; Latino, M.E.; Menegoli, M.; Spennato, A. A survey to discover current food choice behaviors. Sustainability 2019, 11, 5041. [CrossRef] 
8. Blanco, C.A.; Ronda, F.; Perez, B.; Pando, V. Improving gluten-free bread quality by enrichment with acidic food additives. Food Chem. 2011, 127, 1204-1209. [CrossRef]

9. Krupa-Kozak, U.; Troszynska, A.; Baczek, N.; Soral-Smietana, M. Effect of organic calcium supplements on the technological characteristic and sensory properties of gluten-free bread. Eur. Food Res. Technol. 2011, 232, 497-508. [CrossRef]

10. Moroni, A.V.; Arendt, E.K.; Bello, F.D. Biodiversity of lactic acid bacteria and yeasts in spontaneously fermented buckwheat and the sourdoughts. Food Microbiol. 2011, 28, 497-502. [CrossRef]

11. Singh, J.; Whelan, K. Limited availability and higher cost of gluten-free foods. J. Human Nutr. Diet. 2011, 24, 479-486. [CrossRef] [PubMed]

12. Burden, M.; Mooney, P.D.; Blanshard, R.J.; Whiate, W.L.; Cambray-Deakin, D.R.; Sanders, D.S. Cost and availability of gluten-free food in the UK: In store and online. Br. Med. J. 2015, 91, 622-626. [CrossRef]

13. Storsrud, S.; Yman, I.M.; Lenner, R.A. Gluten contamination in oat products and products naturally free from gluten. Eur. Food Res. Technol. 2003, 217, 481-485. [CrossRef]

14. Do, Y.; Choi, J.S.; Jung, Y.K.; Park, J.H.; Roh, K.H.; Kim, S.S.; Choi, S.Y.; Lee, K.Y.; Han, E.J. Evaluation of the level of microbial contamination in the processing company of Nuroong-ji. J. Food Hyg. Saf. 2010, 25, 333-340.

15. Yang, J.W.; Choi, I.S. The physicochemical characteristics and antioxidant properties of commercial Nurungji products in Korea. Korean J. Food Cook. Sci. 2016, 32, 575-584. [CrossRef]

16. Suh, Y.K.; Park, Y.H.; Oh, Y.J. Cooking conditions for the production of instant Nuroongi. J. Korean Soc. Food Nutr. 1996, 25, 58-62.

17. Park, Y.H.; Oh, Y.J. The physiochemical characteristics of instant Nuroong-gi. J. Korean Soc. Food Sci. Nutr. 1997, 26, 632-638. [CrossRef]

18. Cha, B.S. Studies on processing conditions for Nooroong-gi powder by liquefaction and gelatinization of rice powder. Korean J. Soc. Food Sci. 1999, 15, 469-474.

19. Lee, H.S.; Kwon, K.H.; Kim, B.S.; Kim, J.H. Quality characteristics of instant Nuroong-gi to which Dioscorea japonica powder was added. Korean J. Food Preserv. 2009, 16, 680-685.

20. Ha, K.Y.; Yoo, J.S.; Baek, M.K.; Baek, S.H.; Park, H.S.; Cho, Y.C.; Kim, B.K. Comparison of characteristics of Nuroong-gi made from Japonica rice cultivars. J. Food Eng. 2012, 16, 381-385.

21. Choi, I.J.; Kim, D.Y.; Chung, C.H. Quality characteristics of pan bread with Nurungii powder. Culin. Sci. Hosp. Res. 2017, 23, 159-166. [CrossRef]

22. Lee, J.A. Quality characteristics of pressurized Nurungji using green whole grain. Culin. Sci. Hosp. Res. 2018, 24, 29-37. [CrossRef]

23. Park, J.K.; Kim, S.S.; Kim, K.O. Effect of milling ratio on sensory properties of cooked rice and on physicochemical properties of milled and cooked rice. Cereal Chem. 2001, 78, 151-156. [CrossRef]

24. Champagne, E.T.; Bett-Garber, K.L.; McClung, A.M.; Bergman, C. Sensory characteristics of diverse rice cultivars as influenced by genetic and environmental factors. Cereal Chem. 2004, 81, 237-243. [CrossRef]

25. Chung, S.J.; Han, J.Y. Utilizing psychological distances of hedonic phrases to develop a Korean hedonic scale. Food Qual. Pref. 2013, 28, 188-192. [CrossRef]

26. Cho, S.; Yoon, S.H.; Min, J.; Lee, S.; Tokar, T.; Lee, S.O.; Seo, H.S. Sensory characteristics of seolgitteok (Korean rice cake) in relation to the added levels of brown rice flour and sugar. J. Sens. Stud. 2014, 29, 371-383. [CrossRef]

27. Rodriguez-Arzuaga, M.; Cho, S.; Billiris, M.A.; Siebenmorgen, T.; Seo, H.S. Impacts of degree of milling on the appearance and aroma characteristics of raw rice. J. Sci. Food Agric. 2015, 51, 2406-2415. [CrossRef]

28. Champagne, E.T.; Bett, K.L.; Vinyard, B.T.; Webb, B.D.; McClung, A.M.; Barton, F.E.; Lyon, B.G.; Moldenhauer, K.; Linscombe, S.; Kohlwey, D. Effect of drying conditions, final moisture content and degree of milling on rice flavor. Cereal Chem. 1997, 74, 566-570. [CrossRef]

29. Kim, M.K.; Lee, Y.J.; Kwak, H.S.; Kang, M.W. Identification of sensory attributes that drive consumer liking of commercial orange juice products in Korea. J. Food Sci. 2013, 78, S1451-S1458. [CrossRef]

30. Kim, M.K.; Lopetcharat, K.; Drake, M.A. Influence of packaging information on consumer liking of chocolate milk. J. Dairy Sci. 2013, 96, 4843-4856. [CrossRef]

31. Kim, M.K.; Kwak, H.S.; Kim, M.J.; Kim, S.S. Identification of sensory characteristics that drive consumer preferences of commercially mass-produced doenjang in Korea. J. Sens. Stud. 2018, 33, e12323. [CrossRef]

32. Desai, N.T.; Shepard, L.; Drake, M.A. Sensory properties and drivers of liking for Greek yogurts. J. Dairy Sci. 2013, 96, 7454-7466. [CrossRef] [PubMed] 
33. Bayarri, S.; Marti, M.; Carbonell, I.; Costell, E. Identifying drivers of liking for commercial spreadable cheeses with different fat content. J. Sens. Stud. 2012, 27, 1-11. [CrossRef]

34. Leksrisompong, P.P.; Lopetcharat, K.; Guthrie, B.; Drake, M.A. Preference mapping of lemon lime carbonated beverages with regular and diet beverage consumers. J. Food Sci. 2013, 78, S320-S328. [CrossRef] [PubMed]

35. Childs, J.L.; Drake, M.A. Consumer perception of fat reduction in cheese. J. Sens. Stud. 2009, $24,902-921$. [CrossRef]

(C) 2020 by the author. Licensee MDPI, Basel, Switzerland. This article is an open access article distributed under the terms and conditions of the Creative Commons Attribution (CC BY) license (http://creativecommons.org/licenses/by/4.0/). 